\title{
Tregs control the development of symptomatic West Nile virus infection in humans and mice
}

\author{
Marion C. Lanteri, ${ }^{1}$ Katie M. O'Brien, ${ }^{2}$ Whitney E. Purtha, ${ }^{2}$ Mark J. Cameron, ${ }^{3}$ \\ Jennifer M. Lund, ${ }^{4}$ Rachel E. Owen, ${ }^{1,5}$ John W. Heitman, ${ }^{1}$ Brian Custer, ${ }^{1}$ Dale F. Hirschkorn, ${ }^{1}$ \\ Leslie H. Tobler, ${ }^{1}$ Nancy Kiely, ${ }^{6}$ Harry E. Prince, ${ }^{7}$ Lishomwa C. Ndhlovu, ${ }^{5}$ Douglas F. Nixon, ${ }^{5}$ \\ Hany T. Kamel,6 David J. Kelvin, ${ }^{3,8}$ Michael P. Busch, ${ }^{1,9}$ Alexander Y. Rudensky,10 \\ Michael S. Diamond, ${ }^{2}$ and Philip J. Norris ${ }^{1,5,9}$
}

\begin{abstract}
${ }^{1}$ Blood Systems Research Institute, San Francisco, California, USA. ²Department of Medicine, Department of Molecular Microbiology, and Department of Pathology and Immunology, Washington University School of Medicine, St. Louis, Missouri, USA. ${ }^{3}$ University Health Network and Department of Immunology, University of Toronto, Toronto, Ontario, Canada. ${ }^{\mathrm{V}}$ accine and Infectious Disease Institute, Fred Hutchinson Cancer Research Center, Seattle, Washington, USA. ${ }^{5}$ Department of Medicine, UCSF, San Francisco, California, USA. ${ }^{6}$ Blood Systems Inc., Scottsdale, Arizona, USA. ${ }^{7}$ Focus Diagnostics, Cypress, California, USA. ${ }^{8}$ Division of Immunology, International Institute of Infection and Immunity, Shantou University Medical College, Shantou, Guangdong, People's Republic of China. ${ }^{9}$ Department of Laboratory Medicine, UCSF, San Francisco, California, USA. ${ }^{10} \mathrm{HHMI}$ and Immunology Program, Memorial Sloan-Kettering Cancer Center, New York, New York, USA.
\end{abstract}

\begin{abstract}
West Nile virus (WNV) causes asymptomatic infection in most humans, but for undefined reasons, approximately $20 \%$ of immunocompetent individuals develop West Nile fever, a potentially debilitating febrile illness, and approximately $1 \%$ develop neuroinvasive disease syndromes. Notably, since its emergence in 1999, WNV has become the leading cause of epidemic viral encephalitis in North America. We hypothesized that CD4 ${ }^{+}$ Tregs might be differentially regulated in subjects with symptomatic compared with those with asymptomatic WNV infection. Here, we show that in 32 blood donors with acute WNV infection, Tregs expanded significantly in the 3 months after index $\left(\mathrm{RNA}^{+}\right)$donations in all subjects. Symptomatic donors exhibited lower Treg frequencies from 2 weeks through 1 year after index donation yet did not show differences in systemic $T$ cell or generalized inflammatory responses. In parallel prospective experimental studies, symptomatic WNV-infected mice also developed lower Treg frequencies compared with asymptomatic mice at 2 weeks after infection. Moreover, Treg-deficient mice developed lethal WNV infection at a higher rate than controls. Together, these results suggest that higher levels of peripheral Tregs after infection protect against severe WNV disease in immunocompetent animals and humans.
\end{abstract}

\section{Introduction}

West Nile virus (WNV), an encephalitic positive polarity RNA virus of the Flaviviridae family, was first isolated in 1937 in the West Nile district of Uganda from the blood of a febrile woman (1). It entered North America in 1999 and spread rapidly across the United States and Canada, and nearly 29,000 symptomatic infections including fever, meningitis, and/or encephalitis and over 1100 deaths have been reported by the CDC (2). Based on blood supply screening and seroprevalence testing, recent estimates suggest that approximately 2 million people have been infected during the epidemic, most with clinically unapparent cases (3).

Considerable progress in understanding the kinetics and mechanisms of viral dissemination and pathogenesis has been made studying WNV infection in rodent models (4). Innate immune responses, interferon secretion $(5,6)$, complement activation (7), and cellular innate immunity $(8,9)$ function to limit the spread and replication of WNV. Studies on the humoral response have established that neutralizing antibodies (10) are also protective (11). $\mathrm{T}$ cell responses also contribute to viral clearance $(12,13)$, as release of proinflammatory cytokines and antigen-restricted CTL responses are seen in mice (14) and humans (15), with perforin and granzymes required for $\mathrm{WNV}$ clearance from the CNS of

Authorship note: Michael S. Diamond and Philip J. Norris contributed equally to this work.

Conflict of interest: The authors have declared that no conflict of interest exists. Citation for this article: J. Clin. Invest. 119:3266-3277 (2009). doi:10.1172/JCI39387. infected mice $(16,17)$. While an intact immune response is clearly key to control of WNV infection (18), an overexuberant immune response may also contribute to disease $(19,20)$.

$\mathrm{CD} 4^{+}$Tregs are able to suppress effector $\mathrm{T}$ cells to prevent or control reactivity to self antigens (21) and pathogens (22), to blunt inflammation (23), and to maintain antigen-specific $\mathrm{T}$ cell homeostasis (24). Multiple Treg populations have been reported (25), with naturally occurring Tregs the most widely studied and best characterized (26). Natural Tregs constitutively express molecules such as CD25 (IL-2 receptor $\alpha$-chain) (27), cytotoxic T lymphocyte-associated antigen 4 (CTLA-4 or CD152) (28), and glucocorticoid-induced TNF receptor (GITR) (29), also expressed by nonregulatory $\mathrm{T}$ cells after activation. More specifically, Tregs express the forkhead/winged helix transcription factor gene forkhead box P3 (Foxp3), described as a key control gene in their development and function (30). More recent studies demonstrate that Tregs also express low levels of CD127 $(31,32)$. While no single marker uniquely identifies Treg populations, panels of markers allow identification of $\mathrm{CD}^{+} \mathrm{T}$ cells with suppressive activity.

In the present study, we explored the hypothesis that Treg levels in individuals with WNV infection associate with disease outcome. Serial samples were collected from a cohort of $\mathrm{WNV}^{+}$blood donors, identified through routine screening for WNV RNA in blood donations. The presence or absence of WNV fever was determined using questionnaires, and effector immune responses and Treg levels were followed for 1 year after infection. Donors who developed symptomatic WNV infection possessed lower Treg levels at each point mea- 
Table 1

Subject characteristics

\begin{tabular}{|c|c|c|c|c|c|c|c|c|c|c|c|c|}
\hline \multirow[t]{2}{*}{ Donor } & \multirow[t]{2}{*}{ Age } & \multirow[t]{2}{*}{ Sex } & \multirow{2}{*}{$\begin{array}{l}\text { Residence } \\
\text { state }\end{array}$} & Before & \multicolumn{3}{|c|}{ Index donation } & \multicolumn{4}{|c|}{ After donation } & \multirow{2}{*}{$\begin{array}{c}\text { Peak } \\
\text { symptom } \\
\text { number }^{B}\end{array}$} \\
\hline & & & & $\begin{array}{c}\text { Symptom } \\
\text { number }\end{array}$ & $\lg M$ & $\operatorname{Ig} G$ & $\begin{array}{c}\text { Symptom } \\
\text { number }\end{array}$ & $\begin{array}{c}\text { After } \\
\text { index (d) }\end{array}$ & $\lg M$ & $\lg G$ & $\begin{array}{c}\text { Symptom } \\
\text { number }\end{array}$ & \\
\hline \multicolumn{13}{|c|}{ Asymptomatic $\leq 3$} \\
\hline $9860^{C}$ & 73 & $\mathrm{~F}$ & Arizona & 2 & - & - & 0 & 7 & - & - & 0 & 2 \\
\hline 650 & 44 & $\mathrm{~F}$ & New Mexico & 0 & - & - & 0 & 10 & + & + & ND & 0 \\
\hline 1150 & 50 & $\mathrm{~F}$ & New Mexico & 0 & - & - & 0 & 12 & + & + & 0 & 0 \\
\hline 1650 & 43 & $\mathrm{~F}$ & North Dakota & 0 & - & - & 0 & 20 & + & + & 0 & 0 \\
\hline 1950 & 24 & $M$ & New Mexico & 0 & - & - & 0 & 14 & + & + & 0 & 0 \\
\hline 2350 & 52 & $M$ & Arizona & 0 & - & - & 0 & 19 & + & + & 0 & 0 \\
\hline 2450 & 73 & $\mathrm{~F}$ & Arizona & 0 & - & - & 0 & 18 & + & + & 0 & 0 \\
\hline 2950 & 25 & $\mathrm{~F}$ & Mississippi & 0 & - & - & 0 & 28 & + & + & ND & 0 \\
\hline 3550 & 57 & $\mathrm{~F}$ & Arkansas & 0 & - & - & 0 & 17 & + & + & 0 & 0 \\
\hline 350 & 60 & $\mathrm{~F}$ & California & 0 & - & - & 0 & 12 & + & - & 1 & 1 \\
\hline 750 & 46 & $\mathrm{~F}$ & Texas & 1 & - & - & 0 & 8 & + & - & 0 & 1 \\
\hline 950 & 55 & $\mathrm{~F}$ & Nevada & 0 & - & - & 0 & 10 & + & + & 2 & 2 \\
\hline 550 & 45 & $\mathrm{~F}$ & South Dakota & 0 & - & - & 2 & 13 & + & + & 3 & 3 \\
\hline 2550 & 39 & $\mathrm{~F}$ & Arizona & 3 & - & - & 0 & 12 & + & + & 0 & 3 \\
\hline 1250 & 75 & $\mathrm{~F}$ & South Dakota & 0 & + & - & 0 & 20 & + & + & 0 & 0 \\
\hline 250 & 36 & $\mathrm{~F}$ & South Dakota & 2 & + & - & 0 & 12 & + & + & 1 & 2 \\
\hline 1450 & 38 & $\mathrm{~F}$ & Texas & 0 & + & + & 0 & 15 & + & + & 1 & 1 \\
\hline 3050 & 59 & $\mathrm{~F}$ & Mississippi & 2 & + & + & 0 & 13 & + & + & 0 & 2 \\
\hline \multicolumn{13}{|c|}{ Symptomatic $\geq 4$} \\
\hline 450 & 47 & $\mathrm{~F}$ & South Dakota & 0 & - & - & 0 & 10 & + & + & 5 & 5 \\
\hline 2650 & 46 & $M$ & Arizona & 0 & - & - & 1 & 15 & + & + & 5 & 5 \\
\hline 1850 & 49 & M & Arizona & 0 & - & - & 2 & 12 & + & - & 5 & 5 \\
\hline 150 & 51 & $M$ & Mississippi & 3 & - & - & 0 & 15 & + & + & 5 & 5 \\
\hline $2250^{\mathrm{D}}$ & 39 & $\mathrm{~F}$ & Mississippi & 1 & - & + & 0 & 12 & + & + & 4 & 4 \\
\hline 1750 & 50 & $\mathrm{~F}$ & Minnesota & 5 & + & - & 0 & 15 & + & + & 2 & 5 \\
\hline 2850 & 31 & $\mathrm{~F}$ & Arizona & 0 & - & - & 4 & 22 & + & + & 5 & 5 \\
\hline 1050 & 54 & M & North Dakota & 4 & - & - & 4 & 10 & + & + & 2 & 4 \\
\hline 3150 & 25 & $\mathrm{~F}$ & South Dakota & 7 & - & - & 0 & 25 & + & + & 4 & 7 \\
\hline 3350 & 38 & $M$ & Texas & 3 & - & - & 2 & 43 & + & + & 8 & 8 \\
\hline 1350 & 72 & $\mathrm{~F}$ & South Dakota & 9 & - & - & 3 & 14 & + & + & 4 & 9 \\
\hline 2050 & 52 & $\mathrm{~F}$ & North Dakota & 4 & - & - & 5 & 12 & + & + & 8 & 8 \\
\hline 850 & 26 & $\mathrm{~F}$ & California & 5 & - & - & 1 & 15 & + & + & 12 & 12 \\
\hline 1550 & 47 & $M$ & Minnesota & 5 & + & + & 2 & 15 & + & + & 5 & 5 \\
\hline
\end{tabular}

ADays between index blood donation and the first study visit, the first sample from which PBMCs and plasma could be isolated. BHighest number of symptoms reported on either questionnaire. ' Donor 9860 seroconverted at day 12 after index donation. ${ }^{D}$ Donor 2250 showed negative WNV plaque-reduction neutralization test at day 10 , with titers rising to $1: 5120$ at day 16 . ND, not done.

sured after infection, even when Treg levels had returned to baseline 1 year after infection. Parallel prospective studies in a mouse model of WNV infection confirmed the observations in humans.

\section{Results}

Study cohort characteristics. From over 800,000 United Blood Services donations screened for WNV in 2005, plasma from 45 donors tested positive for WNV RNA. Thirty-two of these $\mathrm{WNV}^{+}$donors were entered in this study and completed 2 symptom questionnaires administered at enrollment and 2 weeks after index donation. Validation of the questionnaires using donors with acute WNV or an initial false-positive WNV test revealed that of 12 possible symptoms (see Methods), the presence of 4 or more symptoms was associated with true WNV infection (odds ratio 3.28; 95\% CI,
1.71-6.28) (33). Given that up to 3 symptoms were found in noninfected donors, this cutoff was used to designate $\mathrm{WNV}^{+}$donors as asymptomatic (<4 symptoms) or symptomatic ( $\geq 4$ symptoms). The most frequent symptom reported by the asymptomatic population was new skin rash (17\% of asymptomatic), while the symptomatic populations most frequently reported body aches, headache, and weakness ( $88 \%, 76 \%$, and $65 \%$, respectively for symptomatic), then fever or eye pain (53\% each). Most of the donors (81\%) were enrolled while still in a very early phase of infection (WNV RNA ${ }^{+}$IgM-IgG'; Table 1), and all seroconverted within 43 days of donation.

Identification of $C D 4^{+} C D 25^{\text {bi }}$ Tregs. Tregs express several markers, such as CD25 (27), Foxp3 (30), GITR (29), and CTLA-4 (28), yet lack expression of CD127 (34) and are commonly defined as CD $4^{+} \mathrm{CD} 25^{\text {hif }}$ oxp $^{+} \mathrm{T}$ cells. To validate our Treg-gating analy- 
A
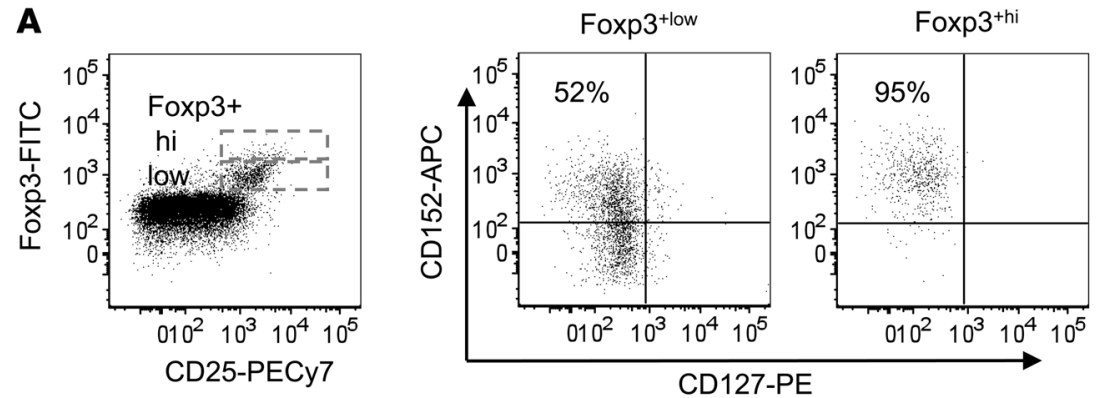

$\mathbf{B}$

CD25 $5^{\text {neg }}$
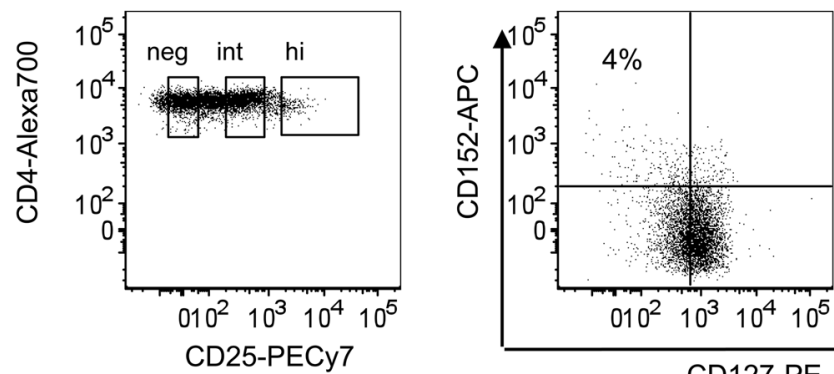

CD25 int

CD25 hi

C
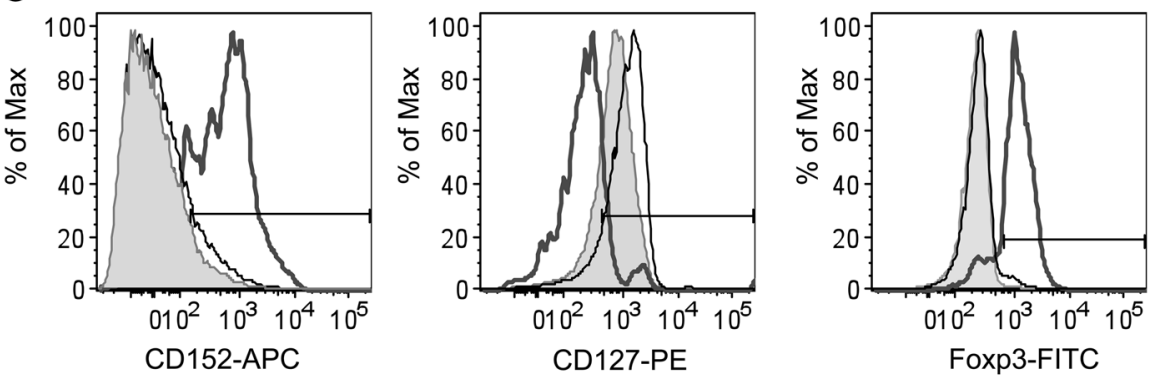

CD25neg

CD25 $5^{\text {int }}$

D

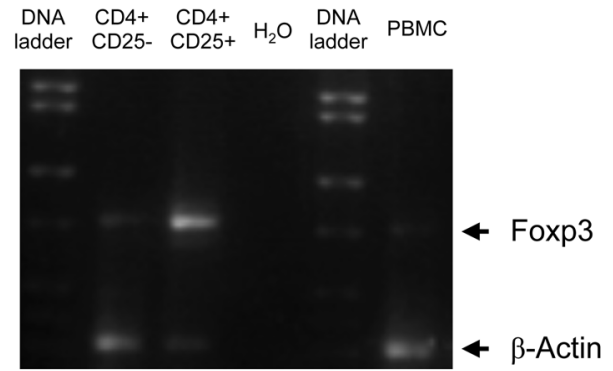

Figure 1

Identification of Tregs. PBMCs were stained ex vivo for CD3, CD4, CD25, Foxp3, CD152, and CD127. Lymphocytes were gated and dead cells excluded. (A) The Foxp3 cell gate was set to exclude Foxp3- and CD25- events within CD3+CD4+ cell populations. CD152+CD127- events were measured in CD25+Foxp3+lo (52\%) and CD25+Foxp3+hi cells (95\%) and in (B) CD25 ${ }^{\text {neg }}(4 \%)$, CD25int $(5 \%)$, and CD25i cells $(63 \%)$. Levels of CD152, CD127, and Foxp3 staining were measured in CD25 ${ }^{\text {eg }}$, CD25 int and CD25 hi populations using selected gates. (C) CD25 hi cells were $68.9 \%$ CD152+, $14.3 \% \mathrm{CD} 127-^{-}$, and $80.7 \%$ Foxp3 $^{+}$, compared with respective values of $13.2 \%, 89.9 \%$, and $3.7 \%$ for CD25int cells and $8.6 \%$, $79.8 \%$, and $0.6 \%$ for CD25 ${ }^{\text {neg }}$ cells. Results are from 1 representative of 3 normal human controls tested in 4 independent experiments. (D) Agarose gel with DNA stained with ethidium bromide. Expression of Foxp3 in CD4+CD25+ $\mathrm{T}$ cells compared with PBMCs or CD4 ${ }^{+} \mathrm{CD} 25^{-} \mathrm{T}$ cells, normalized for RNA input using $\beta$-actin primers (gel representative of 3 different experiments).

sis, normal donor PBMCs were stained for CD3, CD4, CD25, CD152, CD127, and Foxp3. Live $\mathrm{CD}^{+} \mathrm{CD}^{+}$cells were gated for analysis, with further gating on Foxp $3^{+} \mathrm{CD} 25^{+}$cells. The gated $\mathrm{CD}^{+} \mathrm{CD}^{+} \mathrm{CD}^{2} 5^{+} \mathrm{Foxp}^{+}$cells were primarily $\mathrm{CD} 152^{+} \mathrm{CD} 127^{-}$ (Figure 1A). As described by others (31), the $\mathrm{CD}^{+} \mathrm{T}$ cells with the highest expression of CD25 constitutively expressed intracellular CTLA-4/CD152 and had low levels of CD127 (Figure 1B). In addi- tion, $\mathrm{CD} 25^{\text {hi }} \mathrm{CD} 152^{+} \mathrm{CD} 127^{-} \mathrm{T}$ cells expressed more Foxp3 than $\mathrm{CD} 25^{\text {int }}$ or $\mathrm{CD} 25^{\text {lo }}$ populations (Foxp3 mean linear fluorescence intensity $=518,345$, and 282, respectively; Figure 1C). Conversely, $\mathrm{CD}^{+} \mathrm{CD} 25^{\mathrm{hi}} \mathrm{Foxp}^{+} \mathrm{T}$ cells fell in the CD $127^{-} / \mathrm{CD} 152^{+}$gate. Tregs were defined as $\mathrm{CD} 4^{+} \mathrm{CD} 25^{\text {hi }} \mathrm{CD} 152^{+} \mathrm{CD} 127^{-}$

Phenotypic study of $\mathrm{CD} 4^{+} \mathrm{CD} 25^{\text {hi }} \mathrm{CD} 152^{+} \mathrm{CD} 127^{-}$Tregs. $\mathrm{CD} 4^{+} \mathrm{CD} 25^{+}$ and $\mathrm{CD} 4^{+} \mathrm{CD} 25^{\text {neg/int }} \mathrm{T}$ cell populations were purified from PBMCs 
A
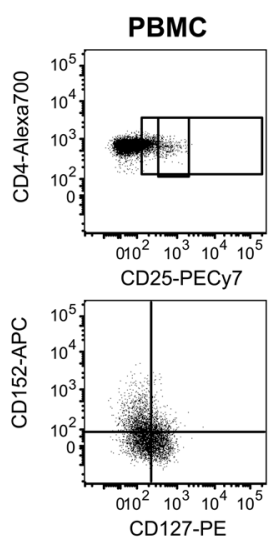

B

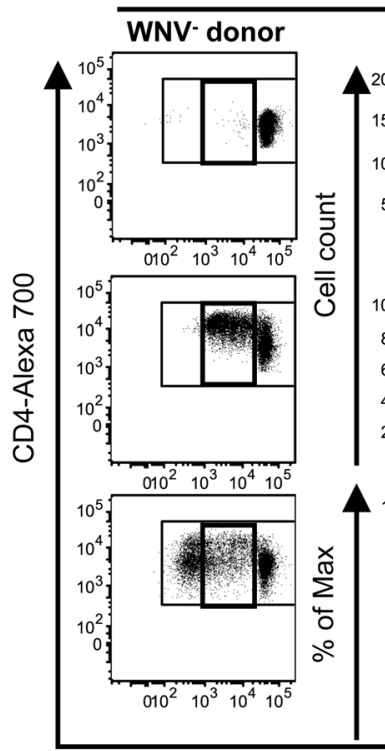

CD25 $5^{\text {hi-depleted }}$
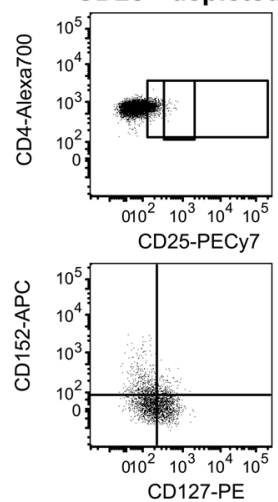

$\mathrm{CD}^{+}$
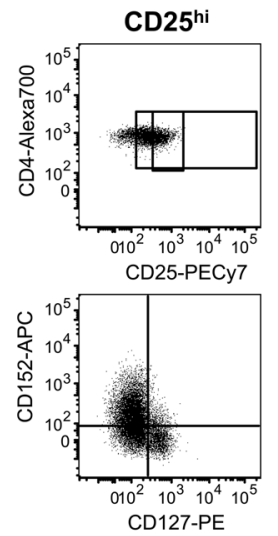

WNV-donor

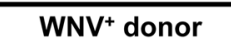

C

Ratio CD4: Tregs

घ1:0

$\square 1: 1$

$\square 2: 1$

प:1

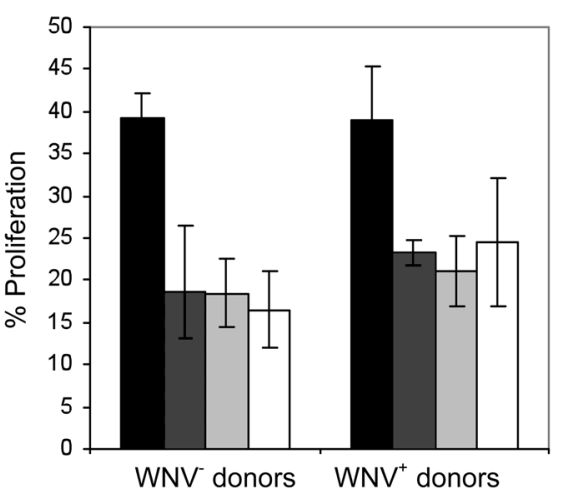

CD4: Tregs 2:1

CD4: Tregs 4:1

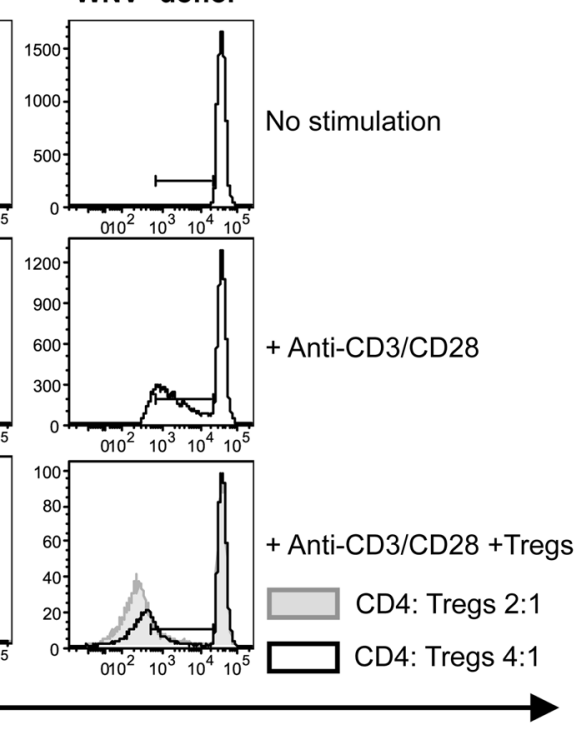

Figure 2

Suppressive capacity of Tregs. (A) Comparison of CD25, CD127, and CD152 expression within CD4+ $\mathrm{T}$ cell fractions before magnetic bead separation (left panels) and after separation within Treg-depleted PBMCs (middle panels) and purified Tregs (right panels) from a normal human control. (B) CD25-depleted CD4+ ${ }^{+}$cells from a normal control and a representative WNV+ donor were stained with $\mathrm{CFSE}^{+}$(CFSE ${ }^{+}$, right peak and middle population). After 4 days of incubation alone, with anti-CD3/CD28, or with anti-CD3/CD28 plus Tregs (CFSE-', left peak), proliferation was analyzed after staining for CD4 and propidium iodide. Tregs were not stained and appear at the far left of the plot. Dot plots are shown for 1 representative WNV- donor. (C) Bar diagrams are representative of $3 \mathrm{WNV}$ - and $3 \mathrm{WNV}+$ donors, with samples collected 30 days after index donation for the $\mathrm{WNV}^{+}$donors. Treg suppression of anti-CD3/CD28-induced proliferation at 4 days is shown at varied effector to Treg ratios, averaging experiments from $3 \mathrm{WNV}^{-}$and $\mathrm{WNV}^{+}$donors (error bars represent SEM).

by magnetic bead separation. Flow cytometric analysis demonstrated enrichment of CD $152^{+} \mathrm{CD} 127-\mathrm{Foxp}^{+} \mathrm{T}$ cells in the $\mathrm{CD} 4^{+} \mathrm{CD} 25^{+}$ population compared with the CD25-depleted population (data not shown). The enrichment in Foxp3-expressing cells was also shown at the transcriptional level by RT-PCR (Figure 1D). To test the functional activity of the cells we identified as Tregs, the isolated $\mathrm{CD} 4{ }^{+} \mathrm{CD} 25^{+} \mathrm{T}$ cell fraction enriched in $\mathrm{CD} 25^{\mathrm{hi}} \mathrm{CD} 152^{+} \mathrm{CD} 127^{-}$cells (Figure $2 \mathrm{~A}$ ) was added back to $\mathrm{CD} 25^{-} \mathrm{CD} 4^{+} \mathrm{T}$ cells stained with CFSE, and cultures were incubated for 4 days in the presence of stimulatory anti-CD3/CD28 antibodies. As anticipated, $\mathrm{CD} 4{ }^{+} \mathrm{CD} 25^{\mathrm{hi}}$ cells inhibited the proliferation of $\mathrm{CD}^{+} \mathrm{CD} 25^{-} \mathrm{T}$ cells (Figure $2 \mathrm{~B}$ ). Tregs from WNV-infected and healthy donors were equally effective at inhibiting proliferation at ratios of responder/Tregs of
$1: 1,2: 1$, or $4: 1$ (Figure 2C). These experiments confirmed that the $\mathrm{CD}^{+} \mathrm{CD} 25^{\mathrm{hi}} \mathrm{CD} 152^{+} \mathrm{CD} 127^{-}$gate identified functional Tregs.

Treg frequency increases following acute WNV infection. Mean $\mathrm{CD} 4^{+} \mathrm{CD} 25^{+} \mathrm{CD} 127^{\text {lo }}$ or Treg frequencies in the $32 \mathrm{WNV}^{+}$donors were compared with those of 17 normal controls. Treg frequencies in $\mathrm{WNV}^{+}$donors increased from $1.47 \%$ at 18 days after index donation to $2.62 \%$ at 90 days after index donation, with a significant increase compared with $\mathrm{WNV}^{-}$donors from 30 days $(P<0.01)$ to 90 days after index donation $(P<0.0001)$ (Figure 3$)$. By 1 year, postindex donation Treg frequencies had returned to a presumed baseline, which was indistinguishable from that of normal donors ( $1.33 \%$ and $1.24 \%$, respectively, $P=0.52)$. These data demonstrate that Tregs expand continuously in humans during and after WNV 

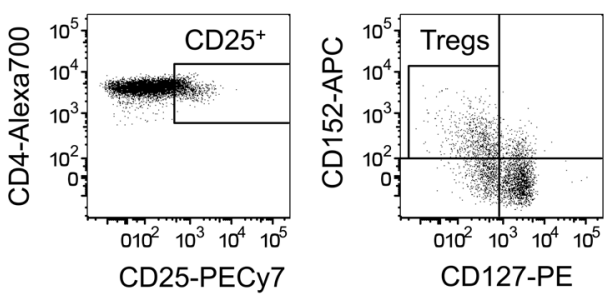

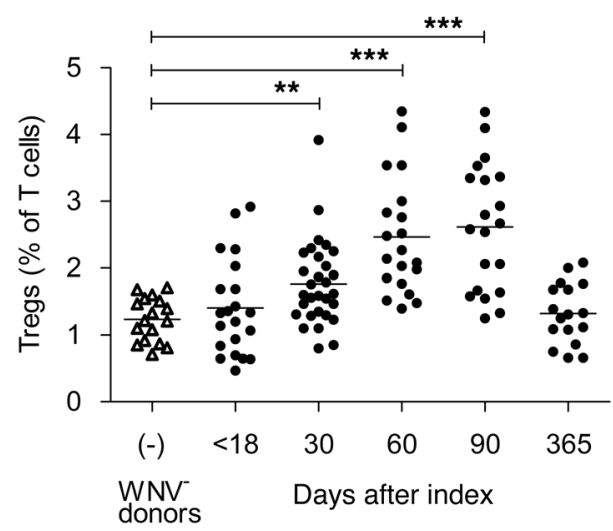

Figure 3

Increased Treg frequencies after WNV infection. Live CD3+CD4+ lymphocytes were gated on CD25+CD127loCD152+ (shaded area, Tregs). Evolution of Treg frequencies expressed as percentage of $\mathrm{CD}^{+} \mathrm{T}$ cells in 17 healthy WNV- donors and in $32 \mathrm{WNV}^{+}$donors at 5 time points after index donation. Twenty-one samples were available for the greater than 18 days time point, 30 at 30 days after index donation, 20 at 60 and 90 days after index donation, 17 at 365 days after index donation. ${ }^{* *} P<0.01 ;{ }^{* * *} P<0.0001$.

for 2 to 3 months after index donation and contract back to a baseline level by 1 year after index donation.

Symptomatic subjects exhibit lower Treg levels than asymptomatic subjects. We hypothesized that higher Treg frequency might correlate with less symptomatic WNV infection. While Tregs might be expected to impede clearance of a potentially chronic infection $(35,36)$, their presence also could ameliorate symptoms caused by "collateral damage" of the immune response to an acute viral infection. Indeed, symptomatic donors had lower frequencies of Tregs than asymptomatic donors from the earliest time point tested through resolution of infection $(P=0.02$ at $<18$ days, $P=0.04$ at 60 days, $P=0.06$ at 365 days after index donation; Figure 4). Analysis using generalized estimating equations showed that Treg frequency was $41 \%$ lower $(95 \%$ CI, $13 \%-60 \%, P=0.008)$ in symptomatic compared with asymptomatic donors across all time periods. Although Treg frequency has been reported to increase with age (37) and nonneuroinvasive yet symptomatic WNV fever is more common in younger subjects (38), we observed no significant difference in the mean age of asymptomatic and symptomatic donors in our cohort (asymptomatic $=48.5$ and symptomatic $=44.8$ years, $P=0.44$ for asymptomatic vs. symptomatic; Figure $5 \mathrm{~A})$ and only a weak correlation between Treg frequency and age ( $r^{2}=0.19$; Figure 5B).

Lower Treg levels are observed in symptomatic versus asymptomatic WNV-infected mice. Because preinfection samples were not available for the human studies, it was impossible to evaluate whether the difference in Treg frequencies between symptomatic and asymptomatic subjects predated WNV infection or whether these differences developed during the first 2 weeks of infection, prior to the first Treg measurement. To test this hypothesis, we compared Treg values with WNV disease outcome phenotypes after infection of C57BL/ 6 mice. Mice were infected with a low inoculum (1 PFU) of a virulent North American WNV strain and followed daily for changes in body weight, appearance, and activity. A group of 20 mice were euthanized at day 8 after infection, and levels of infectious WNV were quantified in the brain and spinal cord. Symptomatic mice (hunchback posture and fur ruffling) showed a concordance among clinical appearance (Figure 6A), weight loss, viral titer in the spinal cord and the brain at day 8 (Figure 6, B-D), and mortality. Another group of 40 mice was followed prospectively, with blood collected preinfection and at days 14 and 28 after infection. At 28 days after infection, the survival rate was $43 \%$ (Figure $6 \mathrm{E}$ ), consistent with prior studies (39). Tregs were defined as $\mathrm{CD} 4{ }^{+} \mathrm{CD} 25^{+} \mathrm{CD} 152^{+} \mathrm{Foxp} 3^{+}$ cells (Figure 6F). Unlike in humans, Treg levels decreased in symptomatic mice that succumbed to WNV infection (Figure 6G). While the mice that died within 28 days of infection had slightly lower preinfection Treg frequencies than those that survived, the difference was not statistically significant $($ died $=4.10 \%$, survived $=5.43 \%$ at day $7, P=0.3$ ). Lower levels of Tregs were observed in blood at day 14 after infection in mice that ultimately succumbed $($ died $=2.93 \%$, survived $=5.80 \%$ at day $14, P=0.004$; Figure 6G). The finding of lower Treg levels at day 14 in mice that ultimately succumbed to infection was analogous to the findings of lower Treg levels in symptomatic humans. Interestingly, an inverse correlation between the level of Tregs and the level of WNV-specific $\mathrm{CD}^{+} \mathrm{T}$ cells was found at day 8 after infection, with animals exhib-

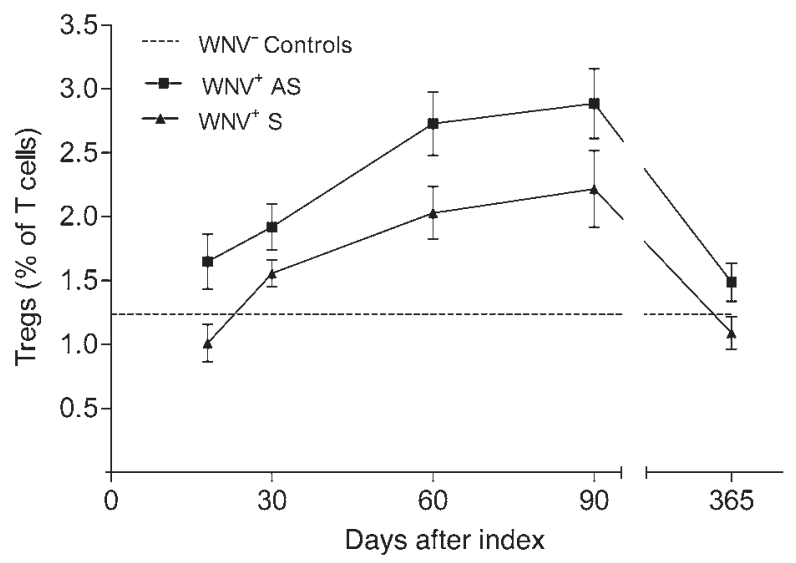

Figure 4

Symptomatic WNV+ donors exhibit lower frequencies of Tregs. Evolution of Treg frequencies in 18 asymptomatic (AS) and 14 symptomatic (S) $\mathrm{WNV}^{+}$donors at 5 time points after index donation. The average Treg frequency in the $17 \mathrm{WNV}^{-}$donors at a single time point is represented by the dotted line. A minimum of 50,000 events were collected in the lymphocyte gate. Error bars represent SEM. 

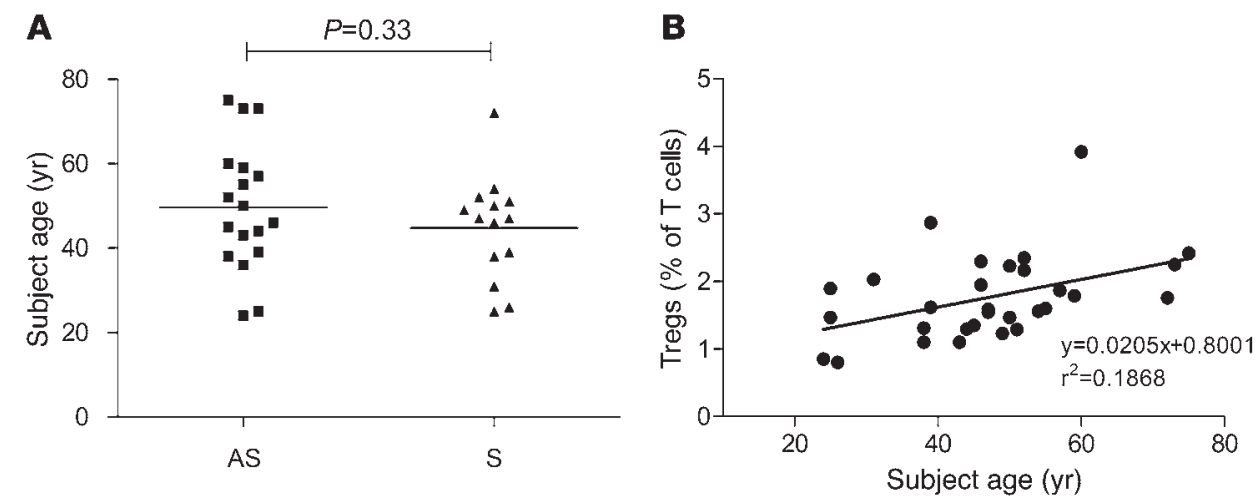

\section{Figure 5}

Age does not confound the relationship between Treg frequency and symptomatic WNV infection. (A) Subject age within the 18 asymptomatic, 14 symptomatic donors; horizontal bars represent mean age. (B) Treg frequencies vs. age of $30 \mathrm{WNV}^{+}$ donors at 30 days after index donation. Correlation coefficient $=0.187$. iting lower $\mathrm{WNV}$-specific $\mathrm{CD}^{+} \mathrm{T}$ cell responses having higher Treg levels $(P=0.012$; Figure $6 \mathrm{H})$, suggesting a possible protective effect of Tregs through dampening of WNV-specific immune responses. Although the WNV infection in mice recapitulates many features of human disease (4), the frequency of severe infection and kinetics of viral dissemination differ between the 2 models, likely accounting for some of the observed disparity in Treg dynamics.

Increased lethality following WNV infection in mice lacking Foxp $3^{+}$Tregs. To confirm the effect of Tregs on WNV infection and disease, we took advantage of Foxp $3^{D T R}$ knockin mice; in these animals Tregs express a diphtheria toxin receptor (DTR) on their cell surface. Treatment of Foxp $3^{D T R}$ mice with diphtheria toxin specifically and completely depletes the $\mathrm{CD} 4^{+} \mathrm{CD} 25^{+} \mathrm{Foxp} 3^{+}$cells $(40,41)$. Foxp $3^{\text {DTR }}$ mice that were treated with DT at day -1 and day 0 relative to infection with WNV showed more frequent and severe symptoms and weight loss $(P<0.01$ and $P=0.02$, respectively; Figure $7 \mathrm{~A})$, resulting in significantly higher mortality rates (93\%) compared with DT-treated or untreated WT mice or untreated Foxp $3^{D T R}$ mice that were infected with WNV (50\%, 46\%, and 44\% mortality, respectively, $P=0.026$; Figure $7 \mathrm{~B})$. Thus, an absence of Tregs at the earliest stage of WNV infection is detrimental to disease outcome in the mouse model.

Adaptive and innate immune mediators in $\mathrm{WNV}^{+}$donors. One possible explanation for the increased Treg frequency in asymptomatic compared with symptomatic human subjects was that these were driven by higher-magnitude effector $\mathrm{T}$ cell responses and/or higher proinflammatory cytokines. To address this, IFN- $\gamma$ production from PBMCs stimulated with 18 amino acid peptides overlapping by 11 residues spanning the entire WNV proteome was quantified by ELISPOT (15). Notably, there was no significant difference between asymptomatic and symptomatic donors in terms of the median number of WNV peptides recognized (asymptomatic $=1$, symptomatic $=1.5$ peptides, $P=0.3$ ) or the magnitude of response $($ asymptomatic $=75$, symptomatic $=120$ spot-forming cells $[\mathrm{SFCs}] / 10^{6} \mathrm{PBMCs}, P=0.2$ ), though the proportion of donors making no detectable $\mathrm{T}$ cell response to WNV trended higher in the asymptomatic group $(P=0.06$; Figure $8, \mathrm{~A}$ and $\mathrm{B})$. As previously demonstrated (42), most $\mathrm{WNV}^{+}$donors seroconverted by 20 days after index donation, with a rapid and transient IgM response and sustained IgG levels (Figure 8C). Again, no significant differences were observed in the kinetics or magnitude of WNV-specific IgM or IgG responses $(P=0.6$ for $\operatorname{IgM}$ and $P=0.7$ for $\mathrm{IgG}$ ) between symptomatic and asymptomatic individuals.

Tregs have complex interactions with cytokine networks that regulate their generation, expansion, and suppressor activity. Functionally important Treg-related cytokines include IL-2 (34),
IL-10 (43), IL-6 (44), and TGF- $\beta$ (45). To determine whether differences in Treg levels correlated with differences in systemic cytokine profiles, 11 asymptomatic and 8 symptomatic $\mathrm{WNV}^{+}$donors (selected based only on specimen availability) were screened for cytokine and chemokine signatures at 5 different time points after index donation, but no significant differences in plasma cytokines or chemokines between asymptomatic and symptomatic WNVinfected donors were observed (Figure 8D).

\section{Discussion}

We describe, for what we believe is the first time, a longitudinal study of Treg frequencies in WNV infection, made possible by screening a large population of healthy blood donors for viral RNA in plasma. Use of questionnaires allowed stratification of the study population into symptomatic and asymptomatic groups. Tregs were defined as $\mathrm{CD} 3^{+} \mathrm{CD} 4^{+} \mathrm{CD} 25^{\mathrm{hi}} \mathrm{CD} 152^{+} \mathrm{CD} 127^{-}$and shown to express Foxp 3 and suppress proliferation. Somewhat surprisingly, Treg levels nearly doubled in the 3 months after infection in spite of only a transient viremia in the study subjects, though potential reservoir sites such as the spleen (39) and kidney (46) were not tested for viral persistence. The major finding of this study was that, compared with asymptomatic donors, those with symptomatic infection had lower Treg frequencies throughout WNV infection and this difference persisted even 1 year after index donation when Treg levels had fallen to a presumed baseline level. To our knowledge, this study shows the strongest correlation of Treg levels with infectious disease outcome in humans reported to date (47).

Risk factors associated with severe WNV infection in humans have been described, including older age, preexisting conditions such as diabetes or hypertension (48), and genetic predisposition, with the same deletion of the CCR5 gene that protects from HIV infection being associated with severe WNV infection (49). Interestingly, the present study revealed lower Treg frequencies in symptomatic $\mathrm{WNV}^{+}$donors even after the contraction phase 1 year after index donation. If the Treg frequency 1 year after index donation is used as a surrogate for the preinfection Treg baseline level, the asymptomatic subjects may have had a higher "Treg tone" prior to infection, with higher preinfection Treg frequencies associated with protection from symptomatic disease. Alternatively, asymptomatic and symptomatic populations may have had similar Treg frequencies prior to infection, but in the first 2 weeks of infection (prior to the first Treg measurement) those with asymptomatic infection had a more robust early Treg expansion.

As a preinfection sample was not available in our donor population, we utilized a well-characterized mouse model of WNV 
A
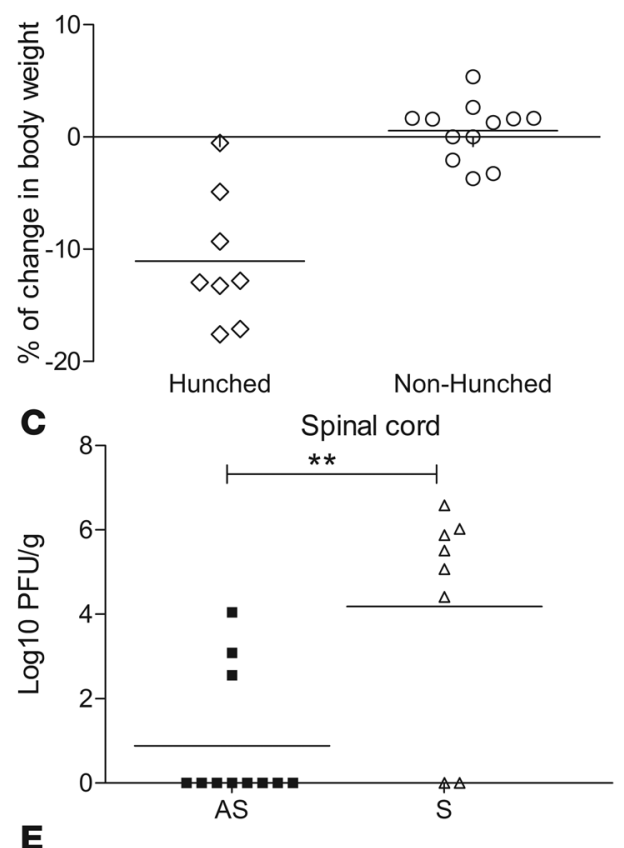

E

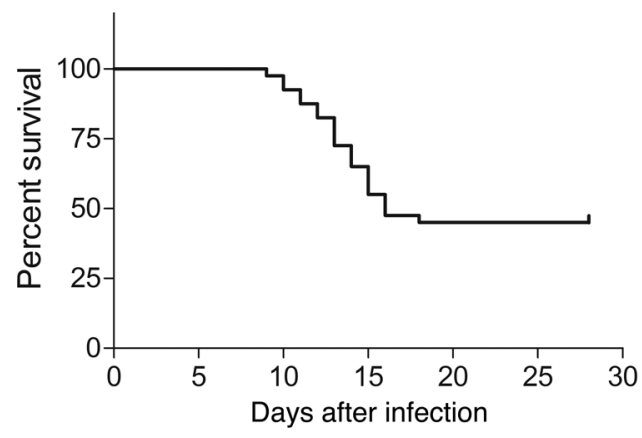

G

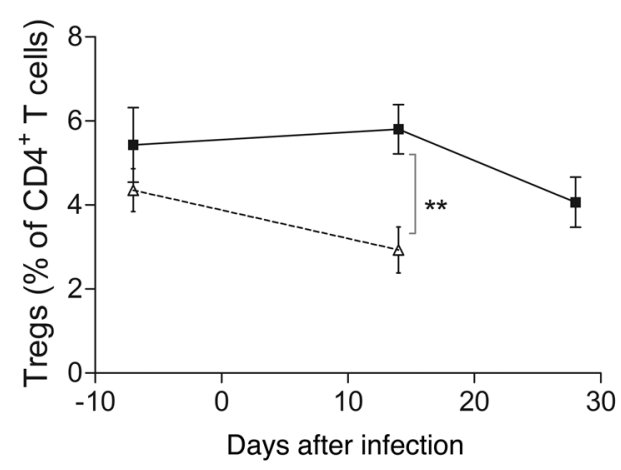

B Virus in the brain vs. \% of change in body weight
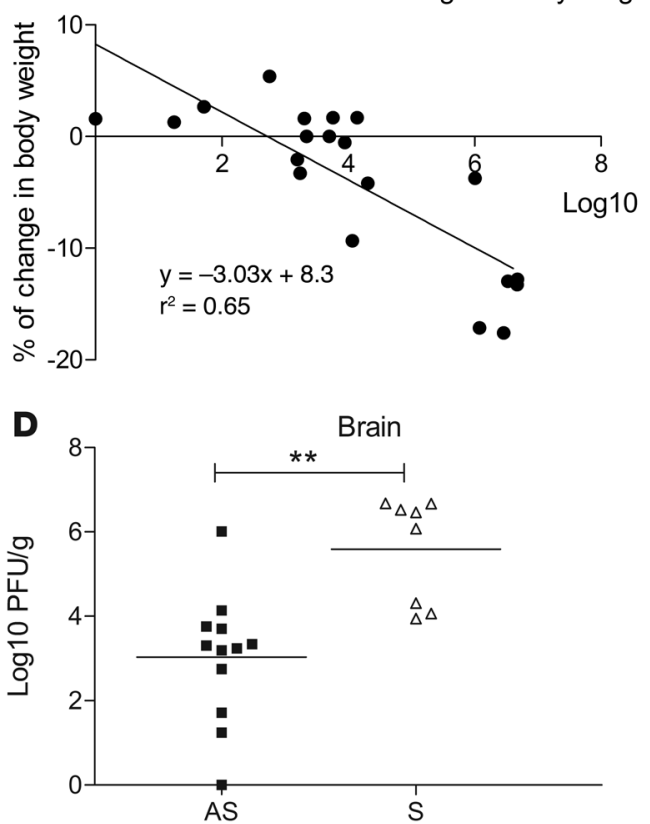

$\mathbf{F}$
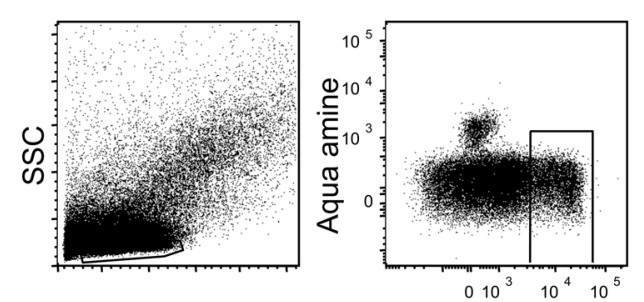

FSC

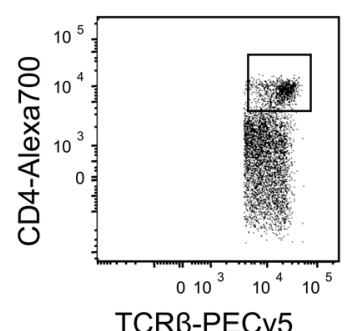

TCRß-PECy 5

- Survived

- $\rightarrow$ - Died

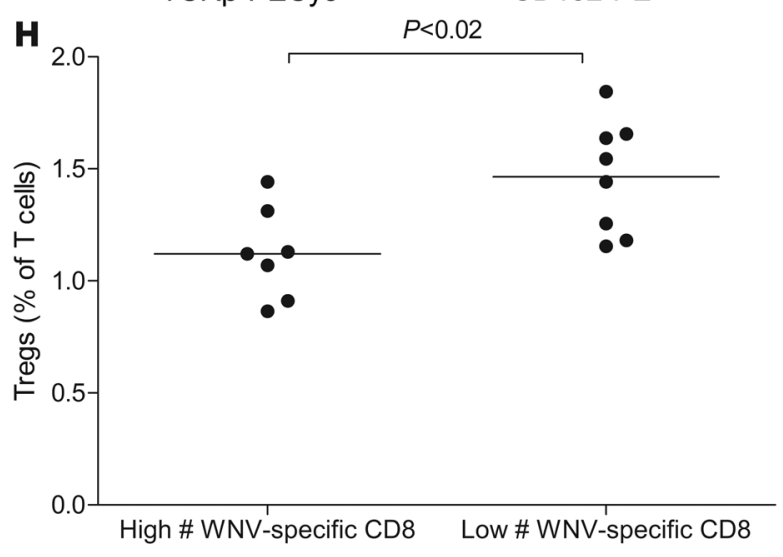




\section{Figure 6}

Lower frequency of Tregs in symptomatic WNV-infected mice. (A) Percentage change in body weight for 8 hunched mice versus 12 nonhunched mice 8 days after infection; horizontal bars represent mean. (B) Correlation between the percentage change in body weight and the amount of WNV in the brain from 20 mice at day 8 after infection. Correlation coefficient $=0.65$. Plaque assay results for viral burden in spinal cord (C) or brain (D) tissues collected from 12 asymptomatic and 8 symptomatic mice from a group of 20 mice sacrificed at day 8 after infection; horizontal bars represent mean. (E) Percentage survival for 40 mice over 28 days after infection. (F) Treg-gating strategy in mouse experiments. PBMCs were stained ex vivo for surface TCR $\beta$, CD4, CD25, and intracellular CD152 and Foxp3. Lymphocytes were gated and dead cells excluded if positive for the Aqua-amine dye. CD152 ${ }^{+}$Foxp $^{+}$Tregs were enumerated among CD4 ${ }^{+}$TCR $\beta^{+}$cells. (G) Treg frequencies in mice that survived to day 28 after infection $(n=17)$ and died prior to day 28 after infection $(n=18)$ are shown before infection and at 14 days after infection. Error bars represent SEM. (H) Association between high Treg frequencies and low WNVspecific CD8 ${ }^{+}$T cells in WT mice $(n=15)$ at 8 days after infection with 1 PFU of WNV. Horizontal bars represent means. Samples were classified as "high" WNV-specific CD8 ${ }^{+} \mathrm{T}$ cells if the value was higher than the mean value for all the samples (3.1\% of splenic T cells at day 8$)$ and "low" if the value was lower than the mean. ${ }^{\star \star} P<0.01$.

infection that in many respects resembles the human disease. Unlike in humans, Treg levels did not increase in mice that survived WNV infection and actually fell in mice that died. Although further study is warranted, one possible explanation for this difference is that mice are more susceptible than humans to WNV and experience symptoms quickly after infection, dying around day 10 to day 14 after infection. Humans are less susceptible to WNV, and symptoms, if they develop, seem to persist for a longer duration, suggesting a slower viral clearance or protracted inflammation. In support of the human data, we observed lower Treg frequencies in symptomatic animals, though this difference did not attain statistical significance at the preinfection time point. Experiments with Foxp $3^{D T R}$ mice (50) showed an accelerated fatal infection with WNV after Treg ablation, establishing a protective role of Tregs in WNV acute infection. As an inverse correlation between the level of Tregs and the level of WNV-specific $\mathrm{CD}^{+} \mathrm{T}$ cells was observed in mice, we speculate that Tregs may exert a protective effect by dampening the WNV-specific immune response and inflammation.

While the current study was built on a unique set of donor specimens, some limitations were inherent in its design. Symptom questionnaires only covered the week before and 2 weeks after index donation, limiting study of long-term effects of WNV infection. Additionally, analysis of peripheral blood may not fully reflect the situation at sites of infection, and lower peripheral Treg levels may not correlate with tissue levels $(39,46,47)$. Furthermore, this study was drawn from a population of healthy donors who did not develop severe, neurological disease. Finally, the correlation between Tregs and disease outcome may not be sustained in subjects with neuroinvasive WNV infection, since high Treg levels, in theory, could impair viral clearance from infected neurons. Against this, however, experiments in mice indicate a net protective role for Tregs during WNV infection.

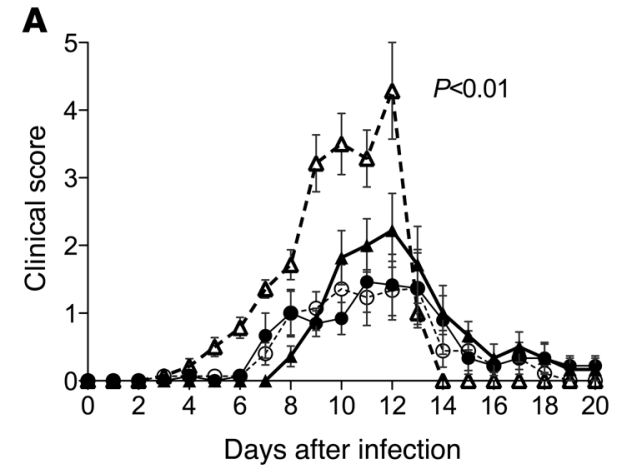

B

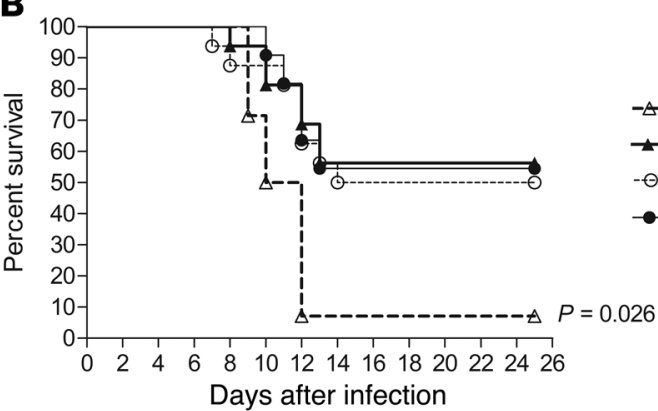

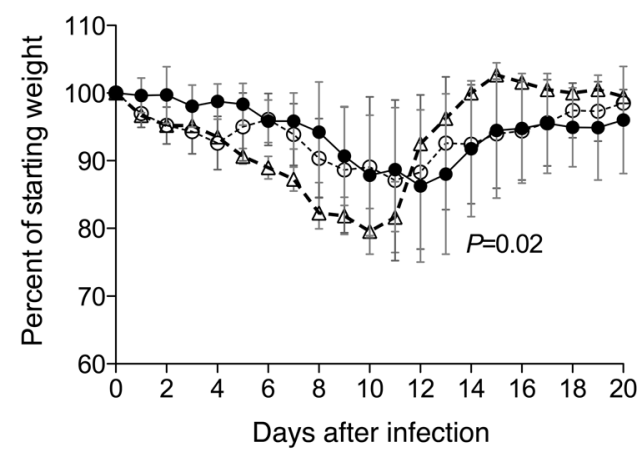

Figure 7

Increased lethality following WNV infection in mice lacking Foxp3+ Tregs. (A) Fifteen untreated WNV-infected WT C57BL/6 mice (WT no DT), 15 DT-treated WNV-infected WT mice (WT + DT), 11 untreated WNV-infected Foxp3 ${ }^{D T R}$ mice (Foxp3-DTR no DT), and 14 DT-treated WNV-infected Foxp3 ${ }^{\text {DTR }}$ mice (Foxp3-DTR + DT) were monitored for clinical scores and weight loss daily. DT treatment was given on day -1 and day 0 . The designation for the clinical scores is as follows: 1, ruffled fur/hunched; 2, paresis/difficulty walking; 3, paralysis; 4, moribund; and 5, dead. After day 12, only 1 Foxp3-DTR (+DT) mouse survived. Error bars represent SEM. (B) The survival data are compiled from 4 independent experiments. $P$ value for WT vs. Foxp3-DTR $(+D T)=0.0086$; Bonferroni corrected $=0.026$. 
A

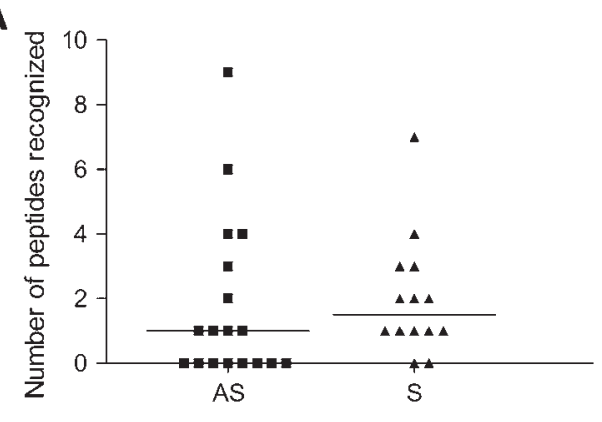

C

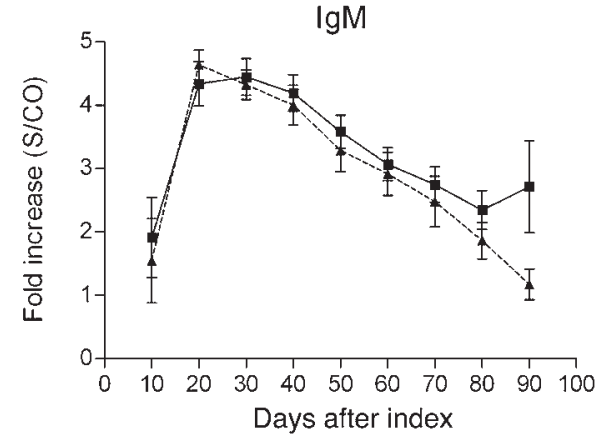

B
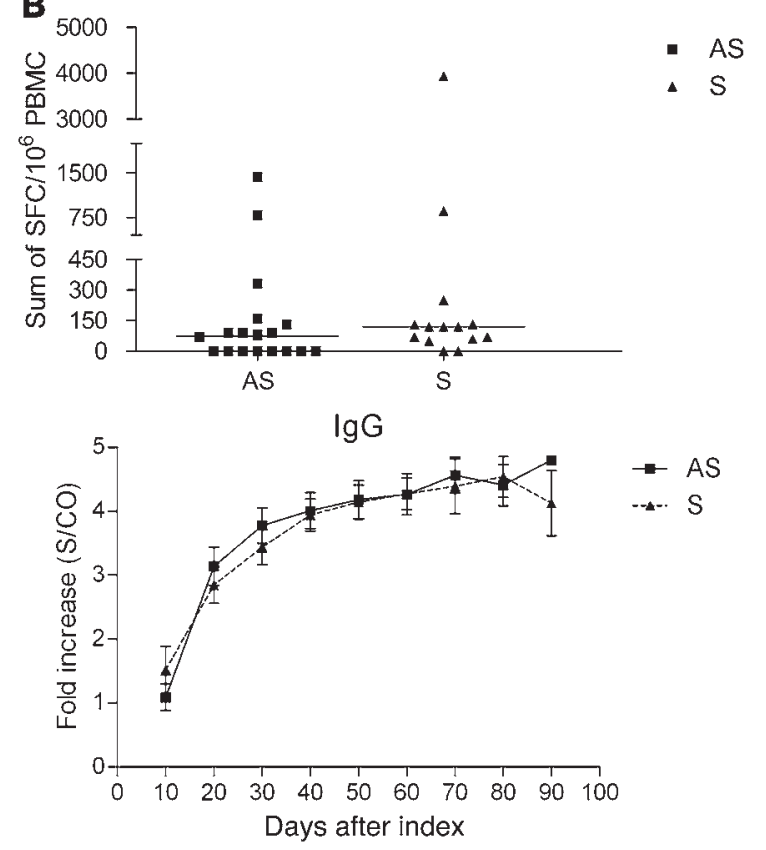

D

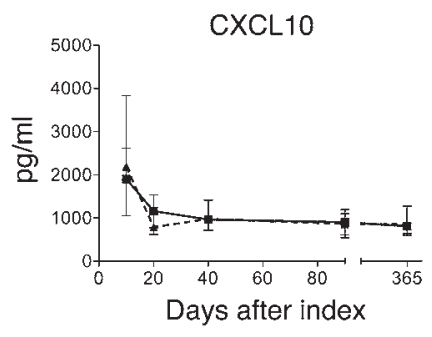

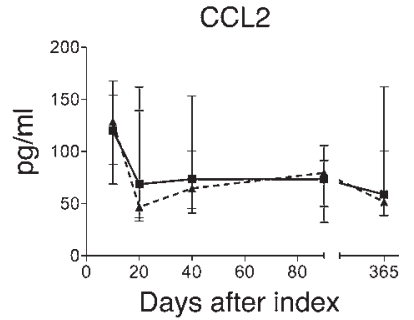

(1.2
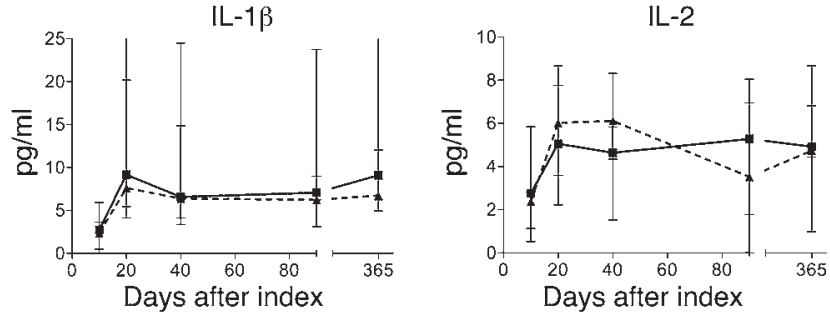

IL-8
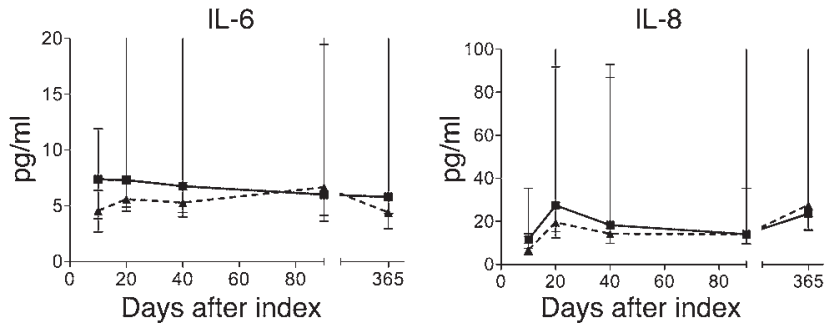

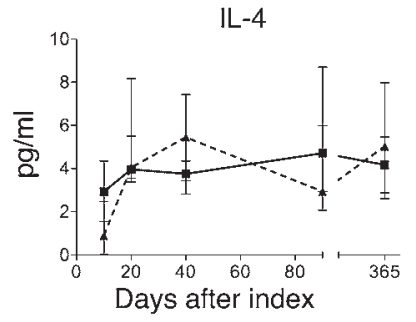

IL-10

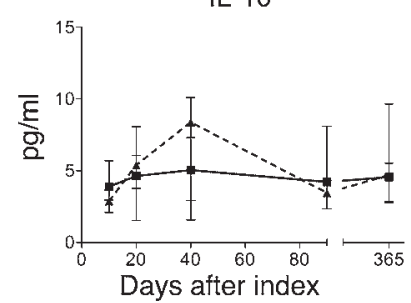

Days after index

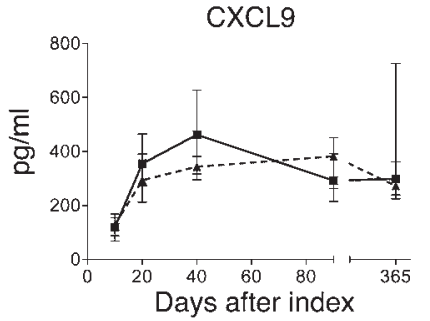

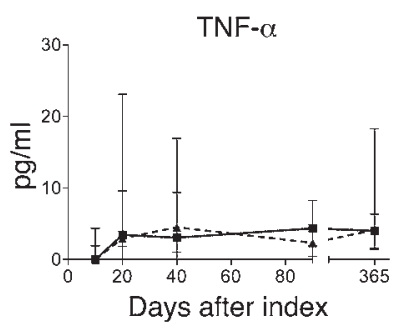
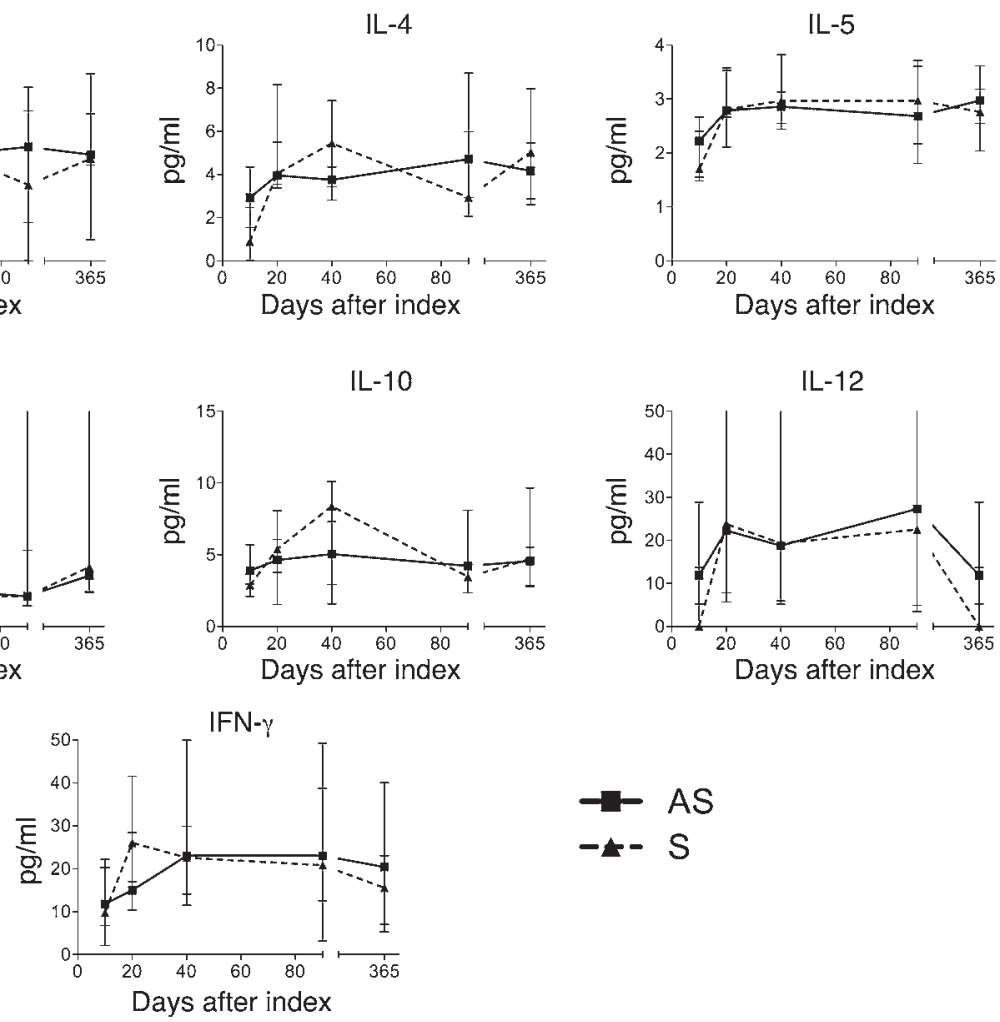

IL-12

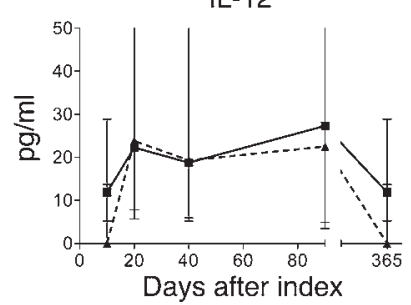

Days after index

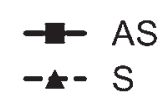




\section{Figure 8}

Similar systemic effector immune responses in symptomatic and asymptomatic human WNV infection. WNV-specific $T$ cell responses during the first 60 days after index donation. Comprehensive analysis of WNV-specific T cell responses by anti-IFN- $\gamma$ ELISPOT assay revealed $(\mathbf{A})$ the median peak number of recognized WNV peptides and $(\mathbf{B})$ the median peak magnitude of responses over 3 time points in the first 60 days after index donation for 18 asymptomatic and 14 symptomatic WNV+ donors. Horizontal bars represent median quantities. (C) IgM and IgG response over the 90 days after index donation in 18 asymptomatic and 14 symptomatic $\mathrm{WNV}^{+}$donors; means with SEM bars are displayed. (D) Cytokine profiles after index donation. Results are shown for analysis of plasma from 11 asymptomatic and 8 symptomatic $\mathrm{WNV}^{+}$donors spanning the year after index donation. Medians with SEM bars are displayed.

The behavior of natural Tregs in humans has been described primarily for tuberculosis and chronic viral infections (51-53). In HCV infection, another Flaviviridae family member, an inverse correlation between Treg number in the periphery of liver biopsies and the histological inflammatory score was reported (54). People chronically infected with HCV have more circulating Tregs in peripheral blood than uninfected people or those who resolve $\mathrm{HCV}$ infection (55). Interestingly, a decrease in Treg number or function was found in the peripheral blood of symptomatic patients infected with HIV (56) or HCV (57), but Treg levels in acute $\mathrm{HCV}$ infection do not predict the ability to clear viremia (58). Tregs have also been studied in dengue virus infection (a Flavivirus that causes acute but not chronic infection), in which Treg expansion but not the absolute level of Tregs was lower in children with severe disease (47). While numerous studies have shown Treg changes in disease states, none have correlated disease outcome with a difference in Treg frequency.

We also explored potential factors that would differentially affect Treg frequencies in the asymptomatic and symptomatic donors. Previous studies reported higher frequencies of Tregs in elderly subjects (37), but age did not correlate with symptomatic status or Treg level in our study cohort. We also examined the general level of immune activation in asymptomatic and symptomatic donors. Asymptomatic donors with higher Treg levels did not possess significantly lower magnitude WNV-specific $\mathrm{T}$ cell responses, although there was a trend to more asymptomatic donors having undetectable effector $\mathrm{T}$ cell responses, whereas mice with higher Treg levels had a lower number of WNV-specific $\mathrm{CD}^{+} \mathrm{T}$ cells. Finally, no difference between asymptomatic and symptomatic $\mathrm{WNV}^{+}$donors was found in their antibody responses or in the accumulation of selected systemic chemokines and cytokines in serum. Future studies will be required to determine the contribution of innate immunity and the mechanisms of induction and action of Tregs, specifically, how they ameliorate clinical outcome after WNV infection. In summary, levels of Tregs appear to predict WNV disease outcome, with higher Treg frequencies in the early phases of infection protecting from symptomatic infection. Although a $\mathrm{CD}^{+} \mathrm{T}$ cell response is required to clear WNV infection (36), an excessive response may cause immunopathology (13). Thus, the downregulation of an effective response by Tregs may be critical for mitigating bystander injury and disease pathology in the CNS. A better understanding of the dynamics, distribution, and function of Tregs may provide new avenues for pharmacologic control of viral pathogenesis.

\section{Methods}

Study design and subjects. From over 800,000 United Blood Services donations screened for WNV in 2005, 45 were confirmed positive for WNV RNA at index donation and reactive on a follow-up sample for anti-WNV IgM antibodies. Of the $35 \mathrm{WNV}^{+}$donors willing to participate after informed consent under UCSF Institutional Review Board approval, symptom questionnaires were successfully completed for the 32 subjects included in the current study. Samples were collected at regional blood centers and shipped via courier to the Blood Systems Research Institute. First PBMC samples were received a mean of 15 days after index donation, with follow-up samples extending to 1 year. Questionnaires covering 12 possible WNV-related symptoms (fever, headache, eye pain, body aches, new skin rash, swollen lymph nodes, nausea or vomiting, muscle weakness, confusion, disorientation, memory problems, or other) were administered at study enrollment and 2 weeks after enrollment. Samples were also drawn from 17 age-matched healthy uninfected negative control subjects (mean age $=42.2$ years for $\mathrm{WNV}^{-} ; 47.4$ years for $\mathrm{WNV}^{+}$; $P=0.12$ ). All $\mathrm{WNV}^{+}$blood donors enrolled in this study tested negative for other blood-borne pathogens, including HIV, HCV, HBV, human T cell lymphotropic virus (HTLV), and syphilis.

WNV RNA and antibody detection. WNV RNA was detected using a Transcription-Mediated Amplification assay (Gen-Probe). Plasma specimens were tested for WNV IgM and IgG using ELISA kits (Focus Diagnostics). An IgG sample-to-calibrator ratio (SCR) of greater than 1.5 and an IgM SCR of greater than 1.1 were considered positive. Time windows of 10 days were selected for assessment of WNV antibody persistence. Multiple results available for a given donor within a given time window were averaged.

Virus. The lineage I WNV strain (3000.0259) isolated in New York in 2000 (WNV-NY) was propagated once in C6/36 Aedes albopictus cells and used for in vivo experiments. For survival comparisons between WT and Foxp $3^{\text {DTR }} \mathrm{C} 57 \mathrm{BL} / 6$ mice, the WNV strain TX 2002-HC was used as previously described (5).

Animal experiments. Mice were bred under pathogen-free conditions. Eight- to twelve-week-old WT of congenic Foxp $3^{\text {DTR }}$ C57BL/6 mice were inoculated subcutaneously with WNV via the footpad. Diphtheria toxin was administered intraperitoneally $(50 \mu \mathrm{g} / \mathrm{kg})$ at day -1 and $(30 \mu \mathrm{g} / \mathrm{kg})$ at day 0 . Mice were genotyped and bred in the animal facilities of the Washington University School of Medicine, and experiments were performed with approval of the Washington University Animal Studies Committee.

Isolation of PBMC and T cell subpopulations: human samples. Plasma was collected after centrifugation, and PBMCs were isolated on a Ficoll-Paque PLUS density gradient (GE Healthcare Life Sciences). Aliquots of $10 \times 10^{6}$ cells were frozen in medium containing $90 \% \mathrm{FBS}$ (HyClone) and $10 \%$ DMSO (Fisher BioReagents) and stored in liquid nitrogen. $\mathrm{CD} 4{ }^{+} \mathrm{CD} 25^{+}$cells were positively isolated with magnetic beads using a human $\mathrm{CD} 4{ }^{+} \mathrm{CD} 25^{+} \mathrm{Reg}-$ ulatory T Cell Isolation Kit (Miltenyi Biotec). The average purity of the $\mathrm{CD} 4{ }^{+} \mathrm{CD} 25^{+}$fraction was $86 \%$ ( 3 independent experiments) after a negative-selection enrichment step for $\mathrm{CD} 4^{+} \mathrm{T}$ cells followed by a second-step positive selection for $\mathrm{CD} 25^{+}$cells and negative selection for $\mathrm{CD} 25^{-}$cells.

Isolation of PBMC and T cell subpopulations: mouse samples. Blood was collected preinfection and on day 8, 14, or 28 after infection. PBMCs were isolated by Percoll gradient centrifugation, washed, and frozen in RPMI $1640,40 \% \mathrm{FBS}$, and $10 \%$ DMSO prior to characterization.

RT-PCR. mRNA was isolated from $\mathrm{CD} 4{ }^{+} \mathrm{CD} 25^{+}$or $\mathrm{CD} 4^{+} \mathrm{CD} 25^{-} \mathrm{T}$ cell subsets using an RNeasy Mini Kit (QIAGEN). Analysis of Foxp3 gene expression by RT-PCR was performed using a QIAGEN OneStep RT-PCR Kit. Primers used for RT-PCR were as follows: $\beta$-actin, forward: 5 '-AGCCTCGCCTTTGCCGA-3' and reverse: 5'-CTGGTGCCTGGGGCG-3'; Foxp3, forward: 5'-CACTGGGGTCTTCTCCCTC-3' and reverse: 5'-TGTGCAGACTCAGGTTGTGG-3' (Operon Biotechnologies Inc.). 
Flow cytometry: human samples. PBMCs were incubated with ethidium monoazide for live cell gating. Stains included anti-CD14-TriColor, antiCD16-PECy5, anti-CD19-PECy5, anti-CD4-Alexa Fluor 700, anti-CD127$\mathrm{PE}$, and anti-CD25-PECy7 (surface); anti-CD3-Pacific Blue, anti-CD152allophycocyanin (APC), and anti-Foxp3-FITC (intracellular).

Flow cytometry: mouse samples. PBMCs were stained with LIVE/DEAD Aqua-amine (Invitrogen). Stains included anti-TCRD-PECy5, anti-CD4Alexa Fluor 700, and anti-CD25-APC (surface); and anti-CD152-PE and anti-Foxp3-PECy7 (intracellular).

Treg functional assays. $\mathrm{CD} 4^{+} \mathrm{CD} 25^{+} \mathrm{T}$ cells $\left(30 \times 10^{3}\right)$ and the indicated ratio of $\mathrm{CD} 4^{+} \mathrm{CD} 25^{-} \mathrm{T}$ cells labeled with $5 \mu \mathrm{M}$ CFSE (Invitrogen) were cultured for 4 days at $37^{\circ} \mathrm{C}$ and $5 \% \mathrm{CO}_{2}$ in duplicate wells in 96-well round-bottom plates (Corning Costar) with or without $2.5 \mu \mathrm{g} / \mathrm{ml}$ anti-CD3 and anti-CD28 (BD Biosciences). After 96 hours, cells were stained with propidium iodide, anti-CD3-Pacific Blue, anti-CD4-Alexa Fluor 700, and anti-CD25-PECy7 (clone: MA-251) and were analyzed for CFSE dilution by flow cytometry.

WNV-specific $C D 8^{+} T$ cells. For detection of WNV-specific mouse $\mathrm{CD}^{+} \mathrm{T}$ cells, splenocytes were restimulated ex vivo with a class I MHC $\mathrm{D}^{\mathrm{b}}$-restricted immunodominant NS4B WNV peptide (59) and incubated with FITC-conjugated anti-CD8 (BD Biosciences) at $4^{\circ} \mathrm{C}$ for 30 minutes. Subsequently, cells were washed, fixed in $1 \%$ paraformaldehyde, permeabilized, and incubated additionally with Alexa Fluor 488-conjugated anti-IFN- $\gamma$ prior to analysis by flow cytometry.

ELISPOT assays. Peptides were divided into 93 pools of 8 to 10 peptides, with each peptide present in 2 pools. The pattern of responses to the pools identified candidate peptides, which were retested individually in duplicate. PBMCs were plated in 96-well MultiScreen-IP plates (Millipore) precoated with antiIFN- $\gamma$ antibody (mAb1-D1K; Mabtech) at $2 \mu \mathrm{g} / \mathrm{ml}$ in PBS (UCSF Cell Culture Facility). Cells were added at 100,000/well in $100 \mu \mathrm{l}$ RPMI (UCSF Cell Culture Facility) plus 10\% human AB serum (Sigma-Aldrich), $11 \mathrm{mM}$ glucose, $2 \mathrm{mM}$ L-glutamine, $23 \mathrm{mM} \mathrm{NaHCO} 3 \mathrm{P}$, and $50 \mathrm{U}$ penicillin-streptomycin (termed $\mathrm{R} 10 \mathrm{H}$ ). The final concentration of each peptide was $5 \mu \mathrm{g} / \mathrm{ml}$. Duplicate negative control wells (cells plus medium) and a positive control well, $0.5 \mu \mathrm{g} / \mathrm{ml}$ phytohemagglutinin (PHA) (Sigma-Aldrich), were run on each plate. Plates were incubated 20 hours at $37^{\circ} \mathrm{C}$ and $5 \% \mathrm{CO}_{2}$, then washed and incubated at $25^{\circ} \mathrm{C}$ for 60 minutes with biotinylated anti-IFN- $\gamma$ antibody (Mabtech). Plates were washed and incubated with streptavidin-alkaline phosphatase (Mabtech) for 60 minutes at $25^{\circ} \mathrm{C}$. Plates were washed prior to addition of 5-bromo-4chloro-3-indolylphosphate and nitroblue tetrazolium substrates (Bio-Rad). Spots were counted, and results were expressed as SFCs $/ 10^{6}$ PBMCs after background subtraction. Responses in $5 \mathrm{WNV}^{-}$healthy controls ranged from
0 to 30 SFCs $/ 10^{6}$ PBMCs, with over $80 \%$ of wells showing no spots. Responses were counted as positive if they were 3 times above background of the plate and consisted of 50 or more SFCs $/ 10^{6}$ PBMCs.

Cytometric bead array analysis of plasma cytokines and chemokines. Plasma was available for 19 of the 32 panels described above and was analyzed by human Th1/Th2 cytokine, inflammation, and chemokine Cytometric Bead Array (CBA) kits (BD Biosciences) according to the manufacturer's protocols (60). Residual plasma volume was insufficient for testing on the remaining 13 subjects. Results were analyzed using BD CBA Analysis Software.

Mouse viral burden measurements. After extensive perfusion with PBS, organs were removed and homogenized; titers were determined by viral plaque assay on BHK21-15 cells as described (39).

Statistics. For Gaussian distributed data, statistical significance was evaluated using a Student's 2-tailed $t$ test and, where appropriate, a 2-tailed, unpaired Student's $t$ test. Differences were considered significant if the $P$ value was less than 0.05 . For non-Gaussian distributed data (i.e., cytokine and chemokine measurements, viral burden data), the nonparametric MannWhitney rank sum test for 2 independent populations was performed using GraphPad Prism software (GraphPad Software). For comparison of survival curves, the log-rank (Mantel-Cox) test with Bonferroni's correction for multiple comparisons was performed using GraphPad Prism software. For comparison of multiple longitudinal measurements (e.g., Treg frequencies), the mean value at each time period was calculated using generalized estimating equation regression for panel data within groups of subjects defined by whether they had symptomatic or asymptomatic WNV infection using Stata 9.0SE software (Stata Corp.). We used robust standard errors to account for multiple observations (serial bleed samples) from these individuals.

\section{Acknowledgments}

This work was supported by CDC R01-C1000214 and U54 AI057160 (Midwest Regional Center of Excellence for Biodefense and Emerging Infectious Diseases Research) and National Institute of Allergy and Infectious Diseases (HHSN266200400066C).

Received for publication March 31, 2009, and accepted in revised form August 19, 2009.

Address correspondence to: Philip J. Norris, Blood Systems Research Institute, Masonic Avenue, San Francisco, California 94118, USA. Phone: (415) 923-5769; Fax: (415) 567-5899; E-mail: pnorris@bloodsystems.org.
1. Hayes, E.B., et al. 2005. Virology, pathology, and clinical manifestations of West Nile virus disease. Emerg. Infect. Dis. 11:1174-1179.

2. Centers for Disease Control. 2009. West Nile virus activity - Human disease cases reported. 20052009. http://www.cdc.gov/ncidod/dvbid/westnile/ surv\&control.htm.

3. Busch, M.P., et al. 2006. West Nile virus infections projected from blood donor screening data, United States, 2003. Emerg. Infect. Dis. 12:395-402.

4. Samuel, M.A., and Diamond, M.S. 2006. Pathogenesis of West Nile Virus infection: a balance between virulence, innate and adaptive immunity, and viral evasion. J. Virol. 80:9349-9360.

5. Keller, B.C., et al. 2006. Resistance to alpha/beta interferon is a determinant of West Nile virus replication fitness and virulence. J. Virol. 80:9424-9434.

6. Wang, T., et al. 2003. IFN-gamma-producing gamma delta $\mathrm{T}$ cells help control murine West Nile virus infection. J. Immunol. 171:2524-2531.

7. Mehlhop, E., et al. 2005. Complement activation is required for induction of a protective antibody response against West Nile virus infection. J. Virol.
79:7466-7477.

8. Ben-Nathan, D., Huitinga, I., Lustig, S., van Rooijen, N., and Kobiler, D. 1996. West Nile virus neuroinvasion and encephalitis induced by macrophage depletion in mice. Arch Virol. 141:459-469.

9. Vargin, V.V., and Semenov, B.F. 1986. Changes of natural killer cell activity in different mouse lines by acute and asymptomatic flavivirus infections. Acta Virol. 30:303-308.

10. Sanchez, M.D., et al. 2005. Characterization of neutralizing antibodies to West Nile virus. Virology. 336:70-82.

11. Ben-Nathan, D., et al. 2003. Prophylactic and therapeutic efficacy of human intravenous immunoglobulin in treating West Nile virus infection in mice. J. Infect. Dis. 188:5-12.

12. Sitati, E.M., and Diamond, M.S. 2006. CD4+ Tcell responses are required for clearance of West Nile virus from the central nervous system. J. Virol. 80:12060-12069.

13. Wang, Y., Lobigs, M., Lee, E., and Mullbacher, A. 2003. CD8+ T cells mediate recovery and immunopathology in West Nile virus encephalitis. J. Virol.
77:13323-13334

14. Lobigs, M., Arthur, C.E., Mullbacher, A., and Blanden, R.V. 1994. The flavivirus nonstructural protein NS3 is a dominant source of cytotoxic T cell peptide determinants. Virology. 202:195-201.

15. Lanteri, M.C., et al. 2008. Comprehensive analysis of west nile virus-specific $\mathrm{T}$ cell responses in humans. J. Infect. Dis. 197:1296-1306.

16. Shrestha, B., Samuel, M.A., and Diamond, M.S. 2006. CD8+ T cells require perforin to clear West Nile virus from infected neurons. J. Virol. 80:119-129.

17. Wang, Y., Lobigs, M., Lee, E., and Mullbacher, A. 2004. Exocytosis and Fas mediated cytolytic mechanisms exert protection from West Nile virus induced encephalitis in mice. Immunol. Cell Biol. 82:170-173.

18. Pealer, L.N., et al. 2003. Transmission of West Nile virus through blood transfusion in the United States in 2002. N. Engl. J. Med. 349:1236-1245.

19. Arjona, A., et al. 2007. Abrogation of macrophage migration inhibitory factor decreases West Nile virus lethality by limiting viral neuroinvasion. J. Clin. Invest. 117:3059-3066. 
20. Wang, T., et al. 2004. Toll-like receptor 3 mediates West Nile virus entry into the brain causing lethal encephalitis. Nat. Med. 10:1366-1373.

21. Sakaguchi, S. 2005. Naturally arising Foxp3expressing $\mathrm{CD} 25+\mathrm{CD} 4+$ regulatory $\mathrm{T}$ cells in immunological tolerance to self and non-self. Nat. Immunol. 6:345-352.

22. Suvas, S., Kumaraguru, U., Pack, C.D., Lee, S., and Rouse, B.T. 2003. CD4+CD25+ T cells regulate virus-specific primary and memory CD8+ T cell responses. J. Exp. Med. 198:889-901.

23. O'Garra, A., and Vieira, P. 2004. Regulatory T cells and mechanisms of immune system control. Nat. Med. 10:801-805.

24. Kumar, V. 2004. Homeostatic control of immunity by TCR peptide-specific Tregs. J. Clin. Invest. 114:1222-1226.

25. O'Garra, A., Vieira, P.L., Vieira, P., and Goldfeld, A.E. 2004. IL-10-producing and naturally occurring CD4+ Tregs: limiting collateral damage. J. Clin. Invest. 114:1372-1378.

26. Shevach, E.M. 2001. Certified professionals: CD4(+)CD25(+) suppressor T cells. J. Exp. Med. 193:F41-F46.

27. Sakaguchi, S., Sakaguchi, N., Asano, M., Itoh, M., and Toda, M. 1995. Immunologic self-tolerance maintained by activated T cells expressing IL-2 receptor alpha-chains (CD25). Breakdown of a single mechanism of self-tolerance causes various autoimmune diseases. J. Immunol. 155:1151-1164.

28. Takahashi, T., et al. 2000. Immunologic self-tolerance maintained by $\mathrm{CD} 25(+) \mathrm{CD} 4(+)$ regulatory $\mathrm{T}$ cells constitutively expressing cytotoxic T lymphocyte-associated antigen 4. J. Exp. Med. 192:303-310.

29. Shimizu, J., Yamazaki, S., Takahashi, T., Ishida, Y., and Sakaguchi, S. 2002. Stimulation of CD25(+)CD4(+) regulatory $\mathrm{T}$ cells through GITR breaks immunological self-tolerance. Nat. Immunol. 3:135-142.

30. Fontenot, J.D., Gavin, M.A., and Rudensky, A.Y. 2003. Foxp3 programs the development and function of CD $4+\mathrm{CD} 25+$ regulatory T cells. Nat. Immunol. 4:330-336

31. Hartigan-O'Connor, D.J., Poon, C., Sinclair, E., and McCune, J.M. 2007. Human CD4+ regulatory T cells express lower levels of the IL-7 receptor alpha chain (CD127), allowing consistent identification and sorting of live cells. J. Immunol. Methods. 319:41-52.

32. Liu, W., et al. 2006. CD127 expression inversely correlates with FoxP3 and suppressive function of human CD4+ T reg cells. J. Exp. Med. 203:1701-1711.

33. Custer, B., Kamel, H., Kiely, N.E., Murphy, E.L., and Busch, M.P. 2009. Associations between WNV infection and symptoms reported by blood donors identified through nucleic acid test screening. Transfusion. 49:278-288.

34. Furtado, G.C., Curotto de Lafaille, M.A., Kutchukhidze, N., and Lafaille, J.J. 2002. Interleukin 2 signaling is required for $\mathrm{CD} 4(+)$ regulatory $\mathrm{T}$ cell function. J. Exp. Med. 196:851-857.

35. McCandless, E.E., Zhang, B., Diamond, M.S., and Klein, R.S. 2008. CXCR4 antagonism increases T cell trafficking in the central nervous system and improves survival from West Nile virus encephalitis. Proc. Natl. Acad. Sci. U. S. A. 105:11270-11275.

36. Shrestha, B., and Diamond, M.S. 2004. Role of CD8+ T cells in control of West Nile virus infection. J. Virol. 78:8312-8321.

37. Sharma, S., Dominguez, A.L., and Lustgarten, J. 2006. High accumulation of T regulatory cells prevents the activation of immune responses in aged animals. J. Immunol. 177:8348-8355.

38. Brown, J.A., et al. 2007. West Nile viremic blood donors and risk factors for subsequent West Nile fever. Vector Borne Zoonotic Dis. 7:479-488.

39. Diamond, M.S., Shrestha, B., Marri, A., Mahan, D., and Engle, M. 2003. B cells and antibody play critical roles in the immediate defense of disseminated infection by West Nile encephalitis virus. J. Virol. 77:2578-2586.

40. Fontenot, J.D., et al. 2005. Regulatory T cell lineage specification by the forkhead transcription factor foxp3. Immunity. 22:329-341.

41. Kim, J.M., Rasmussen, J.P., and Rudensky, A.Y. 2007. Regulatory $T$ cells prevent catastrophic autoimmunity throughout the lifespan of mice. Nat. Immunol. 8:191-197.

42. Prince, H.E., et al. 2005. Development and persistence of West Nile virus-specific immunoglobulin $\mathrm{M}(\operatorname{IgM}), \operatorname{IgA}$, and $\operatorname{IgG}$ in viremic blood donors. J. Clin. Microbiol. 43:4316-4320.

43. Annacker, O., et al. 2001. CD25+ CD4+ T cells regulate the expansion of peripheral CD4 $\mathrm{T}$ cells through the production of IL-10. J. Immunol. 166:3008-3018.

44. Bettelli, E., et al. 2006. Reciprocal developmental pathways for the generation of pathogenic effector TH17 and regulatory T cells. Nature. 441:235-238.

45. Peng, Y., Laouar, Y., Li, M.O., Green, E.A., and Flavell, R.A. 2004. TGF-beta regulates in vivo expansion of Foxp3-expressing CD4+CD25+ regulatory $\mathrm{T}$ cells responsible for protection against diabetes. Proc. Natl. Acad. Sci. U. S. A. 101:4572-4577.

46. Tesh, R.B., et al. 2005. Persistent West Nile virus infection in the golden hamster: studies on its mechanism and possible implications for other flavivirus infections. J. Infect. Dis. 192:287-295.
47. Luhn, K., et al. 2007. Increased frequencies of CD4+ $\mathrm{CD} 25$ (high) regulatory $\mathrm{T}$ cells in acute dengue infection. J. Exp. Med. 204:979-985.

48. Jean, C.M., Honarmand, S., Louie, J.K., and Glaser, C.A. 2007. Risk factors forWest Nile virus neuroinvasive disease, California, 2005. Emerg. Infect. Dis. 13:1918-1920.

49. Lim, J.K., et al. 2008. Genetic deficiency of chemokine receptor CCR5 is a strong risk factor for symptomatic West Nile virus infection: a metaanalysis of 4 cohorts in the US epidemic. J. Infect. Dis. 197:262-265.

50. Lund, J.M., Hsing, L., Pham, T.T., and Rudensky, A.Y. 2008. Coordination of early protective immunity to viral infection by regulatory T cells. Science. 320:1220-1224.

51. Belkaid, Y., and Rouse, B.T. 2005. Natural regulatory $\mathrm{T}$ cells in infectious disease. Nat. Immunol. 6:353-360.

52. Chen, X., et al. 2007. CD4(+)CD25(+)FoxP3(+) regulatory T cells suppress Mycobacterium tuberculosis immunity in patients with active disease. Clin. Immunol. 123:50-59.

53. Manigold, T., and Racanelli, V. 2007. T-cell regulation by $\mathrm{CD} 4$ regulatory $\mathrm{T}$ cells during hepatitis $B$ and $C$ virus infections: facts and controversies. Lancet Infect. Dis. 7:804-813.

54. Cabrera, R., et al. 2004. An immunomodulatory role for CD4(+)CD25(+) regulatory $\mathrm{T}$ lymphocytes in hepatitis $C$ virus infection. Hepatology. 40:1062-1071.

55. Sugimoto, K., et al. 2003. Suppression of HCV-specific T cells without differential hierarchy demonstrated ex vivo in persistent HCV infection. Hepatology. 38:1437-1448.

56. Kinter, A.L., et al. 2004. CD25(+)CD4(+) regulatory $\mathrm{T}$ cells from the peripheral blood of asymptomatic HIV-infected individuals regulate CD4(+) and CD8(+) HIV-specific T cell immune responses in vitro and are associated with favorable clinical markers of disease status. J. Exp. Med. 200:331-343.

57. Boyer, O., et al. 2004. CD4+CD25+ regulatory T-cell deficiency in patients with hepatitis C-mixed cryoglobulinemia vasculitis. Blood. 103:3428-3430.

58. Smyk-Pearson, S., et al. 2008. Functional suppression by FoxP $3+\mathrm{CD} 4+\mathrm{CD} 25$ (high) regulatory $\mathrm{T}$ cells during acute hepatitis $\mathrm{C}$ virus infection. J. Infect. Dis. 197:46-57.

59. Purtha, W.E., et al. 2007. Antigen-specific cytotoxic $\mathrm{T}$ lymphocytes protect against lethal West Nile virus encephalitis. Eur. J. Immunol. 37:1845-1854.

60. Tobler, L.H., et al. 2008. Interferon and interferoninduced chemokine expression is associated with control of acute viremia in West Nile virus-infected blood donors. J. Infect. Dis. 198:979-983. 